OPEN ACCESS

Edited by:

Feng Wang,

Affiliated Hospital of Nantong

University, China

Reviewed by:

Zhenyu Ju,

Jinan University, China

Wei Zhu,

Guangdong Medical University, China Zheying Zhang,

Xinxiang Medical University, China

${ }^{*}$ Correspondence:

Beihui $\mathrm{He}$

graf303@sina.com

Shuo Zhang

zhangshuotcm@163.com

${ }^{\dagger}$ These authors have contributed equally to this work

Specialty section:

This article was submitted to Molecular and Cellular Oncology,

a section of the journal

Frontiers in Oncology

Received: 22 August 2021 Accepted: 06 October 2021

Published: 27 October 2021

Citation:

Chen S, Fang $Y$, Sun L, He R,

He $B$ and Zhang $S$ (2021)

Long Non-Coding RNA: A Potential

Strategy for the Diagnosis and

Treatment of Colorectal Cancer.

Front. Oncol. 11:762752.

doi: 10.3389/fonc.2021.762752

\section{Long Non-Coding RNA: A Potential Strategy for the Diagnosis and Treatment of Colorectal Cancer}

\author{
Shanshan Chen ${ }^{1 \dagger}$, Yi Fang ${ }^{1,2 \dagger}$, Lingyu Sun ${ }^{1,2 \dagger}$, Ruonan $\mathrm{He}^{2}$, Beihui $\mathrm{He}^{1 *}$ and Shuo Zhang ${ }^{1 *}$ \\ 1 The First Affiliated Hospital, Zhejiang Chinese Medical University, Hangzhou, China, 2 The First Clinical Medical College, \\ Zhejiang Chinese Medical University, Hangzhou, China
}

Colorectal cancer (CRC), being one of the most commonly diagnosed cancers worldwide, endangers human health. Because the pathological mechanism of $\mathrm{CRC}$ is not fully understood, there are many challenges in the prevention, diagnosis, and treatment of this disease. Long non-coding RNAs (IncRNAs) have recently drawn great attention for their potential roles in the different stages of CRC formation, invasion, and progression, including regulation of molecular signaling pathways, apoptosis, autophagy, angiogenesis, tumor metabolism, immunological responses, cell cycle, and epithelialmesenchymal transition (EMT). This review aims to discuss the potential mechanisms of several oncogenic IncRNAs, as well as several suppressor IncRNAs, in CRC occurrence and development to aid in the discovery of new methods for CRC diagnosis, treatment, and prognosis assessment.

Keywords: long non-coding RNA, colorectal cancer, drug resistance, proliferation, metastasis, occurrence, invasion

\section{INTRODUCTION}

Colorectal cancer (CRC) is one of the most commonly diagnosed cancers worldwide. In the USA, CRC is the third leading cause of cancer mortality in both men and women. There will be over 10,000 new cases in 2020 , and the proportion of young patients is increasing (1). In addition, the incidence rate of CRC in transitioned countries is approximately 4-fold higher than that in transitioning countries (2). Since the pathological mechanism of CRC is not yet fully understood, further studies are urgently needed to identify and develop new effective biomarkers and targets for its diagnosis and treatment.

Long non-coding RNAs (lncRNAs) are non-coding transcripts composed of more than 200 nucleotides that have a variety of regulatory modes. IncRNAs interact with proteins, RNA, and DNA and form RNA-RNA, RNA-DNA, and RNA-protein complexes, allowing them to participate in many important biological processes, such as transcription, intranuclear transport, and genomic imprinting $(3,4)$. Recent studies have shown that lncRNAs are involved in the regulation of CRC occurrence and development. Some oncogenic lncRNAs promote the occurrence, proliferation, invasion, metastasis, and drug resistance of CRC cells, while some lncRNAs suppress the proliferation and metastasis of CRC cells. The potential mechanism of lncRNAs in CRC are combining with proteins to form complexes to regulate the target downstream, affecting miRNA translation, acting as miRNA sponges (ceRNA) or scaffolds, regulating relevant signalling pathways 
and cell cycle progression, as well as the expression of transcriptional factors, ribosomal biogenesis factors, and anti-oncogenes.

Understanding the potential roles of lncRNAs in CRC occurrence, proliferation, invasion, metastasis, and drug resistance, as well as the effects of some suppressor lncRNAs related to CRC, can provide new ideas and countermeasures for the diagnosis, assessment, and treatment of CRC.

\section{LNCRNAS IN COLORECTAL CANCER}

LncRNAs can regulate the occurrence and development of CRC. Some lncRNAs tend to promote cancer cell proliferation, invasion, metastasis, and drug resistance, while others suppress cancer cell proliferation and metastasis. We discuss their roles and related molecular mechanisms in the following sections.

\section{LncRNAs in Colorectal Cancer Occurrence}

LncRNA ubiquitin-like plant homeodomain (PHD) and really interesting new gene (RING) finger domain-containing protein 1 (UHRF1) Protein Associated Transcript (UPAT) expression is significantly upregulated in highly tumorigenic CRC cell lines compared to that in weak tumorigenic and normal cell lines, as evaluated through quantitative reverse transcription-polymerase chain reaction (qRT-PCR) analysis. UPAT stabilizes the UHRF1 protein by interfering with the ubiquitination and degradation mediated by $\beta$-TrCP E3 ubiquitin ligase $(\beta$-TrCP1 and $\beta$ TrCP2), thus promoting the expression of stearoyl-coenzyme A desaturase-1 (SCD1) and sprouty RTK signaling antagonist 4 (SPRY4). UPAT can also upregulate the expression of phosphoglucomutase 1 (PGM1) and G protein-coupled receptor class $C$ group 5 member A (GPRC5A), but the specific mechanism is not yet clear (5). The epigenetic factor UHRF1 regulates transcription by regulating DNA methylation and histone modification and plays a key role in tumor cell proliferation and survival (6). SCD1, SPRY4, PGM1, and GPRC5A are necessary for the transformation of normal cells into cancer cells and their survival and development (7-9). The UHRF1-UPAT axis may be a promising molecular target for the treatment of CRC. However, the regulatory mechanism of UPAT on the expression of PGM1 and GPRC5A requires further study.

Polycomb repressive complex 2 (PRC2) and DEAD box protein 5 (DDX5) associated lncRNA (PRADX), which acts as a cancer driver, is highly expressed in CRC cells and tissues and is mainly distributed in the nucleus. Enhancer of zeste homolog 2 (EZH2), a histone methyltransferase that catalyzes histone $\mathrm{H} 3$ lysine 27 trimethylation (H3K27me3) and epigenetically silences target genes (10), is overexpressed in many cancer types and has been shown to act as an oncogene $(11,12)$. PRADX can bind to the $\mathrm{EZH} 2$ protein through its $1-500 \mathrm{bp} 5$ ' end sequence to recruit PRC2 and DDX5, forming a PRC2/DDX5 complex (13). Activation of the nuclear factor kappa B (NF- $\kappa \mathrm{B})$ pathway promotes the occurrence of colorectal adenocarcinoma. UBXN1 is a UBX domain protein that can inhibit the degradation of $I \kappa \mathrm{B} \alpha$ thus blocking the NF- $\kappa B$ pathway (14). Because the PRC2/DDX5 complex can inhibit the expression of UBXN1, the NF- $\kappa B$ pathway is activated thereby promoting the occurrence of colon adenocarcinoma (15).

LncRNA antisense ncRNA in the abundant in neuroepithelium area (ANA)/B-cell translocation gene 3 (BTG3) locus (ASBEL) is a tumorigenic gene that can be directly activated by the $\mathrm{Wnt} / \beta$ catenin pathway. At the same time, $\beta$-catenin, can also activate the transcription factor TCF3 (16). TCF3 can form a complex with ASBEL to downregulate the expression of the target transcription factor ATF3 and inhibit the development of CRC. The classic $\mathrm{Wnt} / \beta$-catenin signaling pathway plays an important role in regulating proliferation, cell fate, stem and progenitor cell selfrenewal, and tumorigenesis (17-19). The role of this signaling pathway in carcinogenesis was first described in the context of adenomatous polyposis coli (APC) gene mutations. APC mutations are usually acquired early in the onset of most colon cancers (over $80 \%$ ), leading to the cytoplasmic accumulation of $\beta$ catenin, which binds to TCF/Lef1 and shuttles to the nucleus, where it acts as a transcription factor and promotes cell proliferation (20). Thus, the $\beta$-catenin-ASBEL-TCF3-ATF3 pathway may be a promising target for colon cancer treatment.

Cancer susceptibility 21 (CASC21) is significantly upregulated in CRC tissues. Yes1 Associated Transcriptional Regulator (YAP1), a well-studied transcriptional coactivator, is a main downstream effector of the Hippo pathway that plays a critical role in controlling organ size in animals (21). YAP1 is known to be upregulated in some solid tumors, including CRC, and acts as an oncogene that promotes tumor cell proliferation, migration, and invasion $(22,23)$. Therefore, the upregulation of YAP1 promotes the occurrence of CRC. IncRNAs can regulate the mRNA expression of many functional target genes by functioning as competing endogenous RNAs (ceRNAs) that sponge microRNAs (miRNAs) and competitively inhibit the binding of miRNAs to targets $(24,25)$. miRNAs are short noncoding RNA molecules that inhibit the expression of target genes by cutting down mRNA or inhibiting translation (26). CASC21 acts as a ceRNA sponging miR-7-5p to upregulate YAP1 expression and thus promote the occurrence of CRC (27).

The finding of lncRNA tumorigenicity helps us detect CRC at an early stage, and related molecular signaling pathways may provide us with potential targets for treatment (Figure 1, Table 1).

\section{LncRNAs in Colorectal Cancer Cell Proliferation}

Glycolysis-associated lncRNA of colorectal cancer (GLCC1) is an oncogene in CRC, which is involved in the glycolysis of CRC cells (30). Abnormal activation of glycolytic pathways in cancer cells is considered a sign of malignancy (31). GLCC1 stabilizes c-Myc by binding to HSP90 (HSP90AA1) chaperone and preventing cytoplasmic ubiquitination degradation, thereby increasing the transcription level of lactate dehydrogenase A (LDHA) and activating glycolytic metabolism. HSP90, as a protein chaperone, can stabilize transcription factors, protein kinases, and oncoproteins in the tumor signaling pathway (32). C-myc is an important oncogene involved in regulating glucose metabolism 


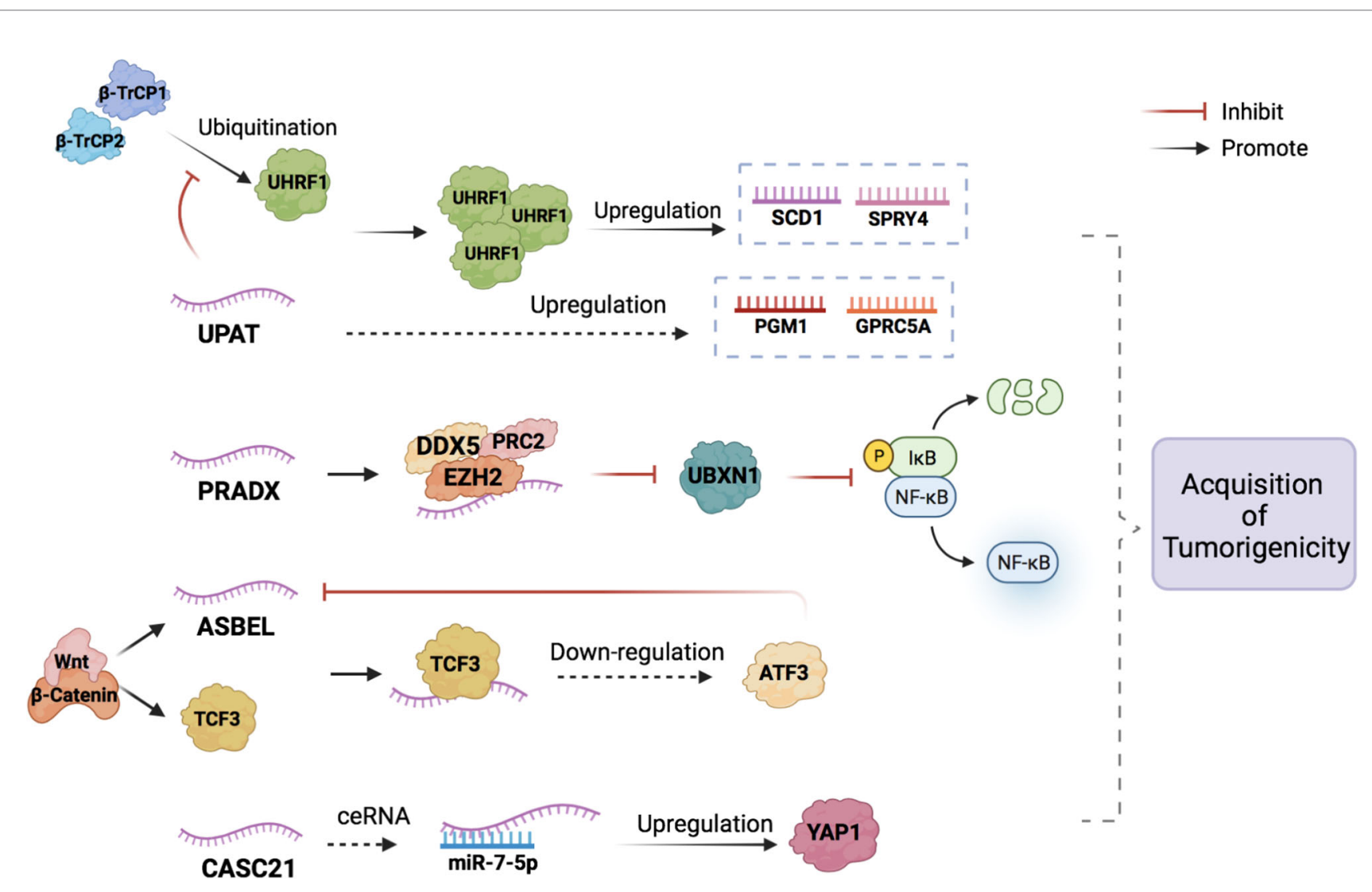

FIGURE 1 | The potential mechanisms of IncRNAs in the CRC occurrence. LncRNAs participate in the acquisition of tumorigenicity of CRC by combining with proteins to form complexes and acting as miRNA sponges (ceRNA).

and is the key on/off switch in cancer cell metabolism. High levels of LDHA expression are associated with poor clinical outcomes of CRC due to its regulation of glycolytic metabolism in cancer cells $(41,42)$. GLCC1-c-Myc-LDHA, as a cascade reaction coordinated by GLCC1 under glucose starvation, may be a promising metabolic blocker target for antitumor therapy.

LncRNA X-inactive specific transcript (XIST) expression in CRC tissues is abnormally high. XIST can target and downregulate mir-486-5p, leading to CRC cell proliferation (43). The miRNA miR-486-5p plays a protective role against $\mathrm{CRC}$, and it acts by obstructing the expression of neuropilin-2 (NRP-2) (44), which is known to interfere with the epithelialmesenchymal transition (EMT) of CRC cells via crosstalk with transforming growth factor $\beta 1$ (TGF- $\beta 1$ ) (33).

The lncRNA colorectal differentially expressed (CRNDE) was originally found to be highly expressed in colorectal adenomas and adenocarcinomas (34). CRNDE targets and upregulates miR-181a-5p. Overexpression of miR-181a-5p reduces the expression of endogenous $\beta$-catenin and TCF4, leading to the inhibition of the Wnt/ $\beta$-catenin signaling pathway. CRNDE binds to miR-181a-5p and blocks its inhibitory effect on Wnt/ $\beta$-catenin signaling, resulting in the proliferation of CRC cells (35). From this perspective, we can hypothesize that it is possible to search for miRNA agonists that can compete against miR-
$181 \mathrm{a}-5 \mathrm{p}$ in binding with CRNDE to inhibit the Wnt/ $\beta$-catenin signaling pathway on the proliferation of colon cancer cells.

LncRNA small nuclear RNA host gene 3 (SNHG3) expression in CRC tissue has been found to be significantly upregulated compared to that in adjacent normal tissues. The binding of SNHG3 and miR-539 can upregulate the expression of its target gene, runt-related transcription factor 2 (RUNX2), to promote cancer cell proliferation (45). RUNX2 is involved in the occurrence and development of a variety of cancers, including CRC, and plays a role as an oncogene $(36,37)$. The authors believe that interfering with the ceRNA mechanism of SNHG3 and blocking its inhibitory effect on miRNA may help suppress the development of CRC.

The expression of lncRNAs BRAF-activated non-coding RNA (BANCR) and chromosome segregation like 1 (CSE1L) has also been found to be significantly upregulated in CRC tissues. BANCR acts as a molecular sponge for miR-203 and separates miR-203 from CSE1L in CRC cells, thus upregulating the expression of CSE1L (46). The upregulation of CSE1L expression, in turn, can promote the proliferation and invasion of cancer cells $(38,47)$. BANCR knockdown suppressed CRC cell proliferation, and CSE1L overexpression reversed the antiproliferation and anti-invasion effects of BANCR silencing (46). Thus, the upregulation of BANCR may promote CRC development through the miR-203/CSE1L axis. 
TABLE 1 | LncRNAs in the occurrence, proliferation, invasion, and metastasis of CRC cells.

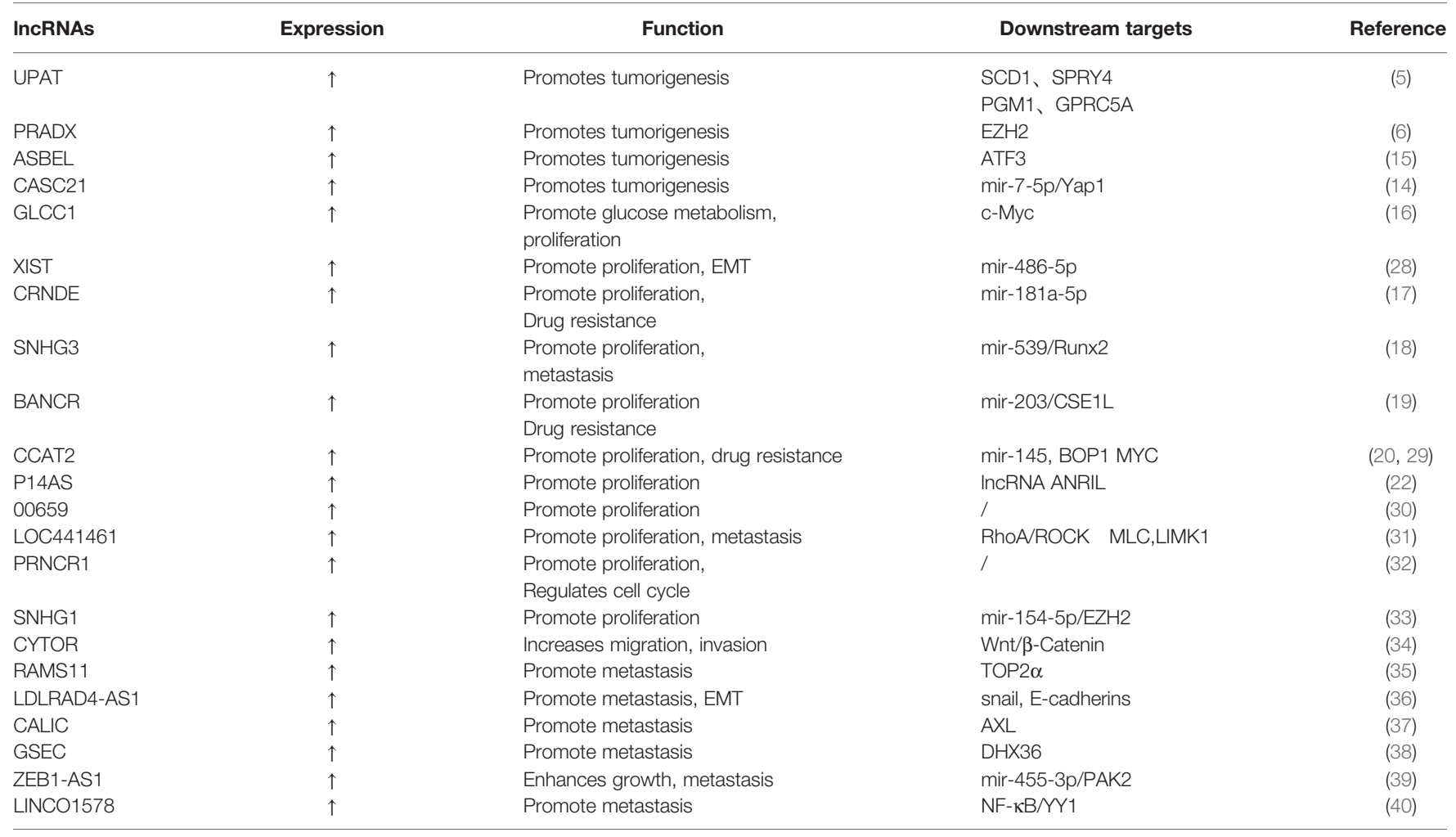

The lncRNA colon cancer-associated transcript 2 (CCAT2), which is overexpressed in CRC tissues, can promote cancer cell proliferation (39). Yu et al. found that miR-145 could modulate the proliferation and differentiation of colon cancer stem cells (CSCs). CCAT2 can selectively inhibit miR-145 maturation by preventing the export of pre-miR-145 to the cytoplasm (39).

P14AS, which binds to AU-rich binding factor 1 (AUF1), is a novel lncRNA transcribed from the antisense strand of the CDKN2A/P14 gene (48). AUF1 is an RNA-binding protein that promotes the expression of many cancer-related RNAs, including c-Myc, P16, and NEAT1 $(40,49,50)$. The carcinogenicity of lncRNA ANRIL (CDKN2B-AS1) has been confirmed in various studies $(51,52)$, and the binding of IncRNA P14AS and AUF1 can increase the levels of ANRIL, resulting in cancer cell proliferation.

Recently, many studies have found that the knockdown of some lncRNAs, such as lncRNA 00659, LOC441461, and lncRNA prostate cancer-associated non-coding RNA 1 (PRNCR1), can inhibit cancer cell proliferation by interfering with the process of the cell cycle (53-55). Among these, the knockdown of LOC441461 expression inhibits the phosphorylation of MLC and LIMK1 by inhibiting RhoA/ROCK signaling, thereby affecting the cell cycle and inducing apoptosis to prevent the proliferation of cancer cells (54).

SNHG1 expression was found to be significantly upregulated in CRC tissues while Kruppel-like factor 2 (KLF2) was downregulated. KLF2 possesses tumor-suppressor features, such as inhibition of cell proliferation and enhancement of DNA damage-associated apoptosis in many cancers (56).
SNHG1 can directly interact with EZH2 to silence KLF2 expression and promote CRC proliferation (29).

The discovery that lncRNAs promote CRC cell proliferation may help improve the prognosis of patients. Studying their specific mechanisms may contribute to the development of new therapeutic targets to inhibit the proliferation of tumor cells (Figure 2, Table 1).

\section{LncRNAs in Colorectal Cancer Cell Invasion and Metastasis}

The lncRNA cytoskeleton regulator RNA (CYTOR) is involved in CRC cell invasion and metastasis via the Wnt/ $\beta$-catenin pathway. CYTOR binds to cytoplasmic $\beta$-catenin and inhibits its phosphorylation induced by kinase 1 (CK1), resulting in $\beta$-catenin accumulation and translocation to the nucleus. At the same time, $\beta$ catenin enhances CYTOR transcriptional activity in the nucleus, thus forming a positive feedback loop. The wound-healing assay showed that CYTOR knockdown inhibited the migration of HCT8 and SW620 cells, and the depletion of CYTOR colon cancer cells failed to induce further invasion. The nude mouse model for lung metastases inoculated with CYTOR-expressing cancer cells showed that the CYTOR knockdown group had a decrease in the size and number of metastatic tumor nodules compared with the control group. This illustrated that CYTOR promoted CRC cell invasion and metastasis both in vivo and in vitro. The upregulation of CYTOR accelerates $\beta$-catenin nuclear translocation and increases the transcription activity of the $\beta$-catenin/TCF complex in the nucleus, activating the $\mathrm{Wnt} / \beta$-catenin pathway to promote cancer cell invasion and metastasis (57). 


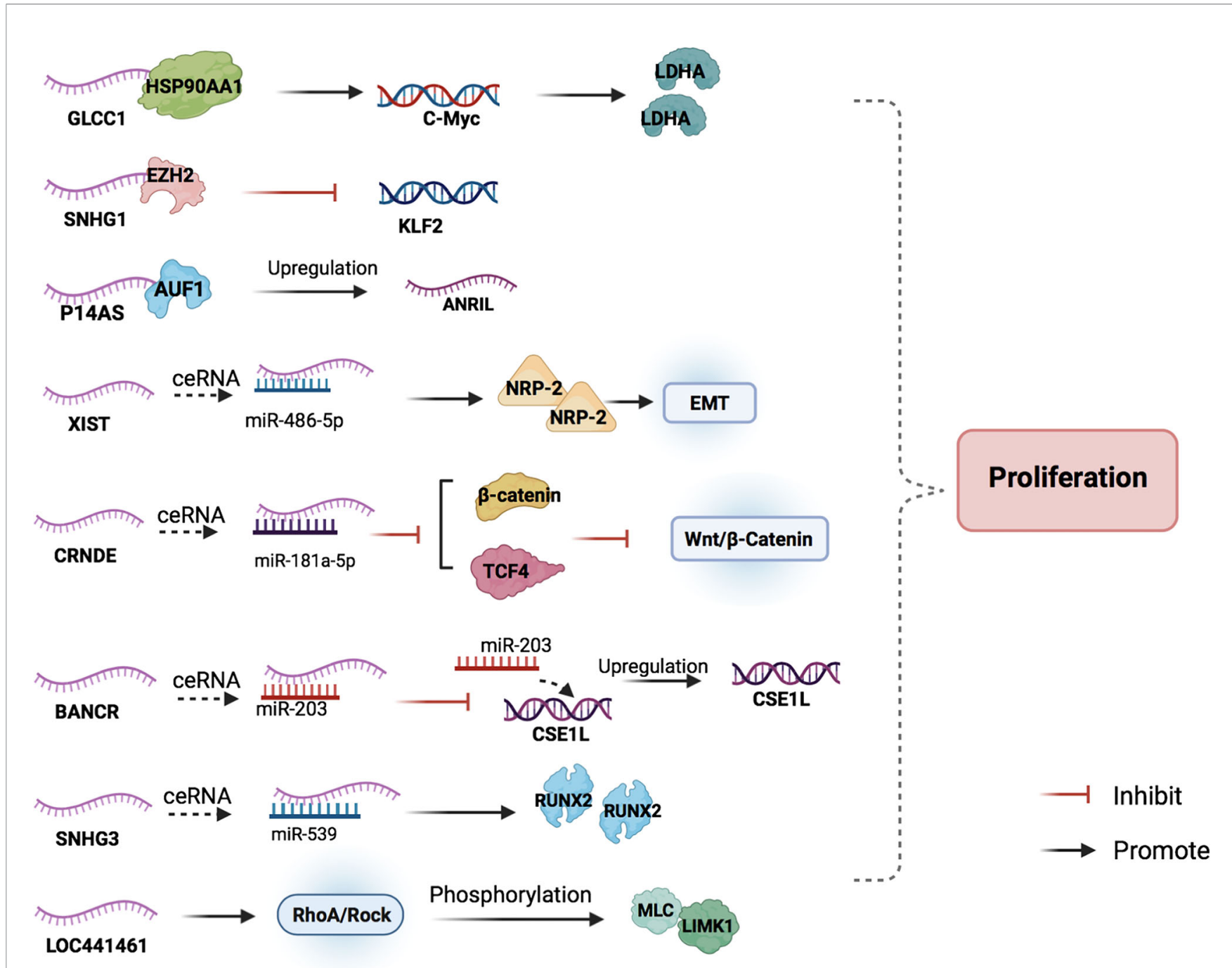

FIGURE 2 | The main mechanisms of IncRNAs in CRC cell proliferation. LncRNAs participate in the CRC cell proliferation by combining with proteins to regulate the target downstream, acting as miRNA sponges, and blocking cell cycle progression.

RNA associated with metastasis 11 (RAMS11) is a lncRNA that can induce tumor formation and promote tumor growth and metastasis. Compared to that in primary tumor tissues, the expression level of RAMS11 was increased in metastatic colon cancer cells. Upon measuring samples from two independent cohorts of colon cancer patients through qPCR, the expression of RAMS11 in metastatic samples was upregulated compared with that in primary cancer tissues. RAMS11 promotes topoisomerase II alpha (TOP2 $\alpha$ ) expression by binding to Chromobox protein 4 (CBX4). Silencing CBX4 or TOP $2 \alpha$ can slow down the invasion and metastasis of LoVo colon cancer cell lines (58). TOP $2 \alpha$ is used as a proliferation marker for many cancer types, including CRC $(59,60)$, and its increased expression levels are associated with prostate cancer, pancreatic cancer, and breast cancer metastases (61-64). In patients with primary and metastatic CRC (mCRC), the expression of TOP $2 \alpha$ is elevated (65-67). RAMS11 promotes the resistance of colon cancer cells to topoisomerase inhibitors, which has become the basic principle for the use of anthracyclines to treat certain mCRC patients (58).

LDLRAD4 antisense RNA 1 (LDLRAD4-AS1) expression levels were reported to be higher in rectal cancer tissues than in adjacent normal tissues. Using the Transwell assay, Mo et al. found that the overexpression of the lncRNA LDLRAD4-AS1 promoted the migration and invasion of highly invasive CRC cell lines (RKO and LoVo) in vitro. LDLRAD4-AS1 also enhanced the migration ability of RKO and LoVo cells in a wound-healing assay. The upregulation of IncRNA LDLRAD4-AS1 expression destabilizes LDLRAD4 mRNA and decreases LDLRAD4 mRNA expression at the protein level, thus reducing the transcription factor snail and E-cadherins, which then promotes epithelial interstitialization and metastasis (68). EMT, marked by the loss of E-cadherin, enables the epithelial cells of a primary tumor to lose cell polarity and break the cellular adhesion constraints, allowing cancer cells to acquire migratory and invasive 
characteristics and be mesenchymal-like towards aggressive malignancy (69-71).

The lncRNA cancer metastasis-associated long intergenic non-coding RNA (CALIC) was significantly upregulated in subpopulations of HCT116 cells that were selected for their elevated metastatic activity. The RNA-Seq and gene ontology (GO) analysis on HCT116 cells that used small interfering RNA (siRNA) to knock down CALIC showed that CALIC target genes are enriched in genes involved in "cell movement" and "cell localization" and that CALIC knockdown inhibits high-level expression CALIC's WiDr colon cancer cell migration. In contrast, the knockdown had little effect on the migration of Caco-2 and Caco-320 colon cancer cells that expressed low levels of CALIC (72). The receptor tyrosine kinase AXL, which regulates FAK1, RHO family GTPases, and GTP exchange factor Vav1, is important in cancer cell migration and invasion. CALIC associates with the RNA-binding protein heterogeneous nuclear ribonucleoprotein L (hnRNP-L) and upregulates $\mathrm{AXL}$, thereby promoting migration and metastasis of colon cancer cells $(73,74)$.

G-quadruplex forming sequence containing lncRNA (GSEC) is enriched in the cytoplasm of colon cancer cells, and its expression is significantly higher than that in the surrounding normal colon tissue. DHX36 is a GSEC-related protein that has the ability to unfold G-quadruplex. Overexpression of DHX36 inhibits the motility of the colon cancer cell line DLD-1. GSEC is a G-quadruplex-containing lncRNA that can bind to DHX36, thus inhibiting the unwinding activity of G-quadruplexes to promote colon cancer cell metastasis (28).

The knockdown of the lncRNA zinc finger E-box binding homeobox 1 antisense 1 (ZEB1-AS1), whose expression level increased in colon adenocarcinoma tissues, suppressed the invasion and migration of SW480 and HT29 cells (75). P21activated kinase 2 (PAK2), a member of the P21-activated kinase (PAK) family of serine/threonine kinases, engages in many signaling pathways related to malignant progression. A study showed that miR-455-3p exhibits anti-cancer effects in colon adenocarcinoma cells by targeting PAK2. ZEB1-AS1 inhibits miR-455-3p and dampens the inhibition of PAK2, thereby promoting cancer cell metastasis (76).

LncRNA LINC01578 activates NF- $\mathrm{BB}$, which, in turn, promotes the expression of LINC01578. Therefore, a positive feedback loop forms between LINC01578 and NF-אB/YY1 (77). $\mathrm{NF}-\kappa \mathrm{B}$ has been shown to promote colon cancer cell invasion and metastasis $(78,79)$, and LINC01578 also exerts a similar effect due to the feedback loop (77).

Studying the signaling pathways of lncRNAs in promoting CRC cell metastasis may help us find potential therapeutic targets for treatment and predict the metastasis rate of the disease (Figure 3 and Table 1).

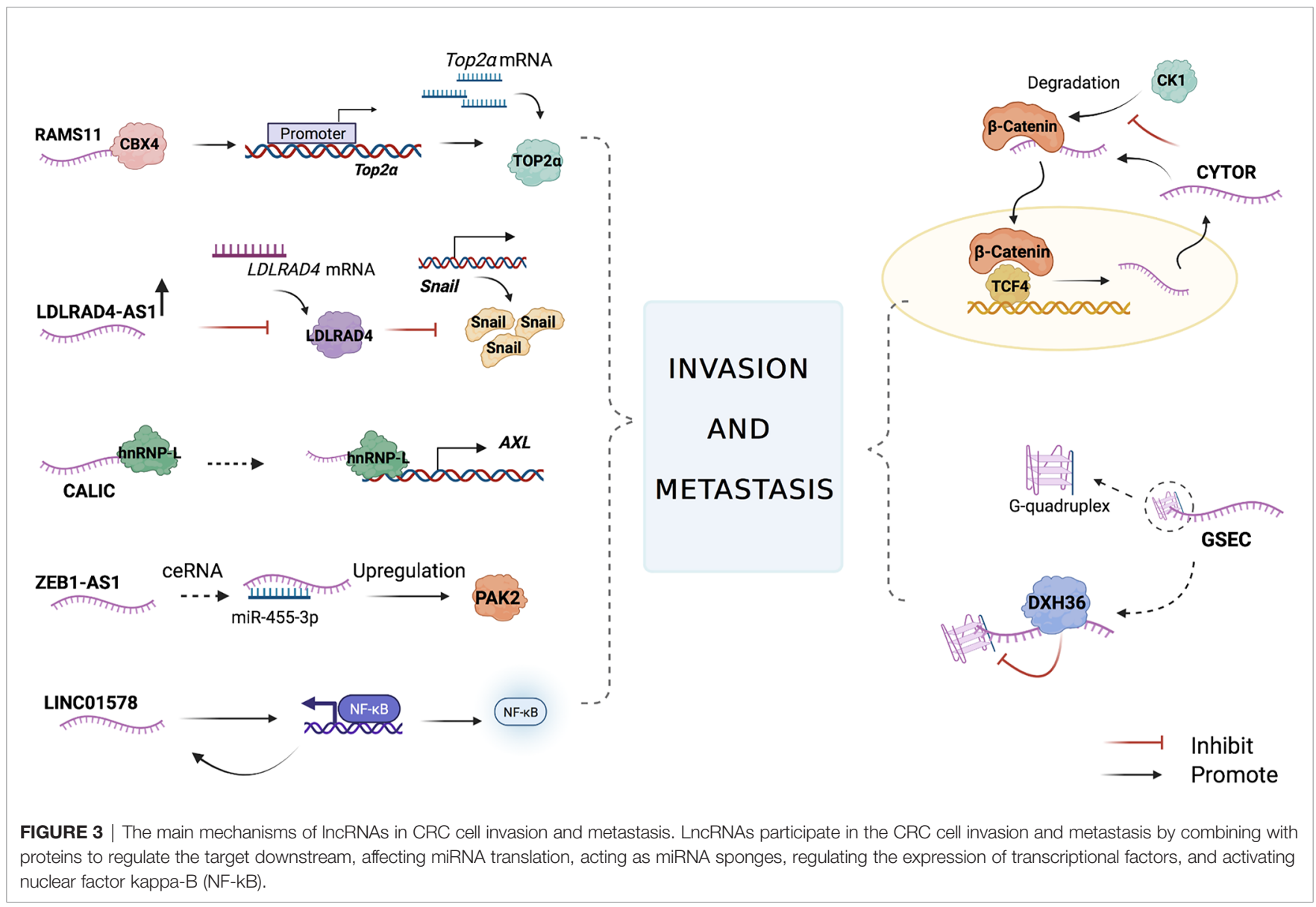




\section{LncRNAs in Colorectal Cancer Cell Drug Resistance}

Currently, improvements in screening, surgical techniques, radiation therapy, and chemotherapy largely contribute to the reduction in the mortality rate of colorectal cancer; however, over $40 \%$ of colorectal cancer patients die from recurrence and metastasis, and multiple-drug resistance in chemotherapy is the main reason for treatment failure. There is strong evidence that supports the effect of lncRNA on the increase in drug resistance in CRC cells (80) (Table 2).

LncRNA H19 is overexpressed in CRC cells and is associated with the immunostaining score of acetaldehyde dehydrogenase 1A1 (ALDH1A1) in H19-high and H19-low CRC specimens (81). ALDH1 A1 is a cancer stem cell marker in colon cancer cells (82), which suggests that $\mathrm{H} 19$ is also associated with the malignant potential of CRC stem cells. Studies have evaluated the chemosensitivity of CRC cells in the routine and widespread use of oxaliplatin, and it has been found that $\mathrm{H} 19$ overexpression promotes oxaliplatin resistance in SW480 and HCT116 cells. In addition, an apoptosis assay confirmed that $\mathrm{H} 19$ overexpression enhanced oxaliplatin resistance in SW480 cells. Cancerassociated fibroblasts (CAFs) are the main type of stromal cells in the CRC tissue matrix, which can transfer H19 into cancer cells by secreting H19-containing exosomes. H19 can then activate the $\beta$-catenin pathway by acting as a ceRNA to sponge miR-141, thus increasing drug resistance in cancer cells (81).

The IncRNA metastasis-associated lung adenocarcinoma transcript 1 (MALAT1) is associated with a poor response to oxaliplatin-based chemotherapy in CRC patients. A study measured the expression level of MALAT1 in the serum of 53 patients with metastatic CRC using qRT-PCR. According to the Response Evaluation Criteria in Solid Tumors (RECIST) criteria, patients were divided into two groups: responsive $(\mathrm{CR}+\mathrm{PR})$ and non-responsive (SD + PD) groups. The results showed that the non-responsive group had significantly higher MALAT1 expression levels compared with the responsive group (83). During oxaliplatin treatment, MALAT1 binds EZH2 to the CDH1 promoter and inhibits miR-128 to promote drug resistance in colorectal cancer cells (84).

The IncRNA CCAT2 promotes the expression of genes involved in ribosome biogenesis and protein synthesis. A CRC cohort study found that lncRNA CCAT2 was positively associated with the expression of BOP1 ribosomal biogenesis factor (BOP1). Chromosomal instability (CIN) can increase chemotherapy sensitivity in colon cancer cells (85). BOP1 can increase the active form of aurora B kinase, which is responsible for regulating chromosomal segregation and promoting CIN, thus increasing drug resistance (86). IncRNA CCAT2 directly interacts and stabilizes BOP1. In addition, it activates the expression of BOP1 by increasing MYC expression.

Lnc00152 is highly expressed in SW620 and HT29 cells at the basal level compared to SW480 and Caco2 cells. As for apoptosis-related genes, Western blot analysis of cleaved poly (ADP-ribose) polymerase (PARP) and cleaved Caspase 3 revealed that SW480 and Caco2 cells are more sensitive to oxaliplatin-induced apoptosis than SW620 and HT29 cells. It has been shown that Lnc00152 upregulates ERBB4 by competitively binding to miR-193a-3p and then activates the AKT pathway, thereby leading to the development of resistance to oxaliplatin (87).

LncRNA MIR4435 expression in cisplatin-resistant colon cancer HCT116 cells is seven to eight times higher than that in normal colon cancer cells, as determined through PCR analysis (88). Nuclear factor erythroid 2-related factor 2 (Nrf2) is a transcription factor that responds to oxidative stress and plays a crucial role in redox homeostasis (89). Heme oxygenase (HO1 ), which is downstream of Nrf2, also plays a role (90). Both are associated with drug resistance and poor prognosis. The lncRNA MIR4435 may increase the cisplatin resistance of colon cancer cells by promoting the expression of $\mathrm{Nrf} 2 / \mathrm{HO}-1$ (91).

LncRNA POU6F2-antisense 2 (POU6F2-AS2) knockdown in colon cancer cell lines leads to the downregulation of the expression of the anti-cancer genes P-gp, MRP2, and BRCA2. Hence, knockdown of lncRNA POU6F2-AS increases the sensitivity of colon cancer cells to cisplatin (92).

Studies on lncRNAs' regulation of chemoresistance in CRC can help predict drug sensitivity to different chemotherapy treatments in patients with CRC and can serve as a guide in adjusting drug use, modifying treatments, and ultimately improving chemotherapy (Figure 4, Table 2).

\section{Inhibitory IncRNAs in Colorectal Cancer}

LncRNAs function not only as oncogenes but also as tumor suppressor genes. Promoting the expression of tumor suppressor lncRNAs may provide a new direction for the treatment of CRC.

LncRNA P53 induced transcript (PINT) expression in primary CRC cells is downregulated compared to that in normal colorectal tissues. The IncRNA PINT is the target of the transcription factor P53, which plays a crucial role in cancer suppression. An in vitro study showed that colon cancer HCT0116 cells overexpressing

TABLE 2 | LncRNAs in CRC cell drug resistance.

\begin{tabular}{lcllc}
\hline IncRNAs & Expression & \multicolumn{1}{c}{ Function } & Downstream targets \\
\hline CCAT2 & $\uparrow$ & Promotedrug resistance, proliferation & mir-145, BOP1 MYC & Reference \\
H19 & $\uparrow$ & Promotes drug resistance & mir-141 & $(20,29)$ \\
MALAT1 & $\uparrow$ & Promotes drug resistance & mir-128 & $(52)$ \\
Linc00152 & $\uparrow$ & Promotes drug resistance & mir-193a-3p, ERBB4 \\
MIR4435 & $\uparrow$ & Promotes drug resistance & Nrf2/HO-1 & $(57)$ \\
POU6F2AS & $\uparrow$ & Promote proliferation, drug resistance & P-gp, MRP2, BRCA2
\end{tabular}




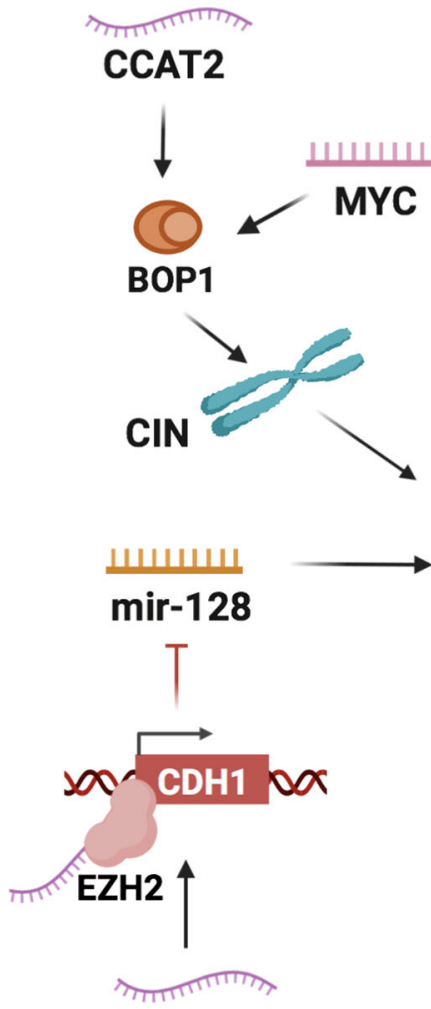

MALAT1

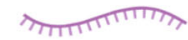

H19

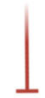

||||||||||

miR-141

000152

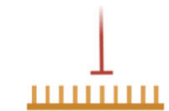

miR-193a-3p

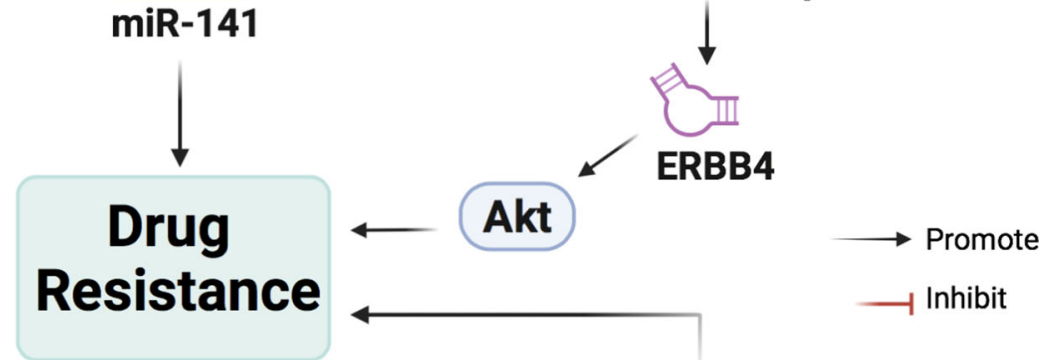

Nrf2

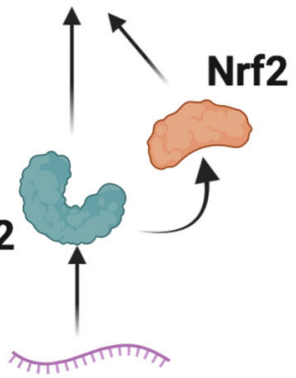

MIR4435

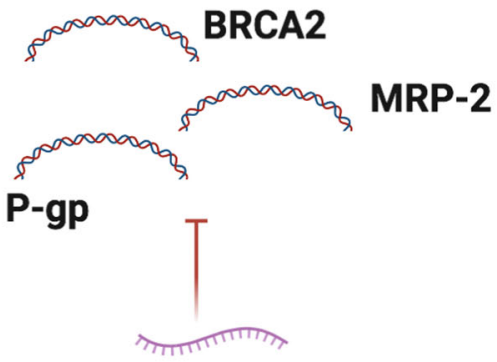

POU6F2-AS2

FIGURE 4 | The main mechanisms of IncRNAs in CRC cell drug resistance. LncRNAs participate in CRC cell drug resistance by acting as scaffolds or miRNA sponges and regulating the expression of transcriptional factors, ribosomal biogenesis factors, and anti-oncogenes.

PINT had a slower growth rate than control cells, but the underlying anti-cancer mechanism has not been revealed (93).

LncRNA loc285194, which is significantly downregulated in CRC cells compared with normal tissues, can also be induced by transcription factor P53. Overexpression of loc285194 inhibited colon cancer HCT-116 and MCF-7 cell proliferation by negatively regulating mir-211 (94).

Maternally expressed 3 (MEG3) is a lncRNA that enhances the sensitivity of CRC cells to chemotherapeutic agents. Its expression in CRC tissues is increased compared with that in adjacent normal tissues. MEG3 knockdown promotes the proliferation, migration, and colony formation of CRC cells and induces G0/G1 cell cycle arrest in these cells (95). MEG3 also acts as a sponge miR-141 to increase the expression of PDCD4 in CRC, which enhances the sensitivity of CRC HCT116 and HT29 cells to oxaliplatin (96).

LncRNA overexpressed in colon carcinoma-1 (OCC-1) knockdown in CRC cells promotes the growth of cancer cells (97). Human antigen $\mathrm{R}(\mathrm{HuR})$ is an RNA-binding protein that can stabilize mRNAs involved in a variety of biological processes. OCC- 1 binds to the HuR protein and increases its interaction with $\mathrm{E} 3$ ubiquitin ligase $\beta$-TrCP1, leading to the ubiquitination and degradation of HuR protein, which suppresses the progression of CRC (98).
The lncRNA tumor suppressor candidate 7 (TUSC7) is involved in inhibiting the migration and invasion of CRC cells. EMT is a key process in inducing migration and invasion $(99,100)$. Zhang et al. detected EMT biomarkers through qRT-PCR and Western blot analysis in CRC cells and discovered that the expression level of TUSC7 is positively associated with the expression of E-cadherin and negatively associated with the expression of vimentin. This indicates that TUSC7 can inhibit EMT in CRC cells to suppress invasion and metastasis (101).

The lncRNA DPP10 antisense RNA 1 (DPP10-AS1) exerts anti-tumor effects on colon cancer cells. It can downregulate the expression of its target gene, miR-127-3p, to increase adenylate cyclase 1 (ADCY1). Thus, it can suppress the proliferation, migration, and invasion of CSCs and increase apoptosis (102).

By identifying more inhibitory lncRNAs in CRC, we can explore the possibility of inhibiting tumor progression by upregulating their expression (Figure 5 and Table 3).

\section{CONCLUSION}

Numerous studies have shown that lncRNAs play an important role in the occurrence and development of CRC. Studying the effects of lncRNAs on cancer cell proliferation, invasion, 


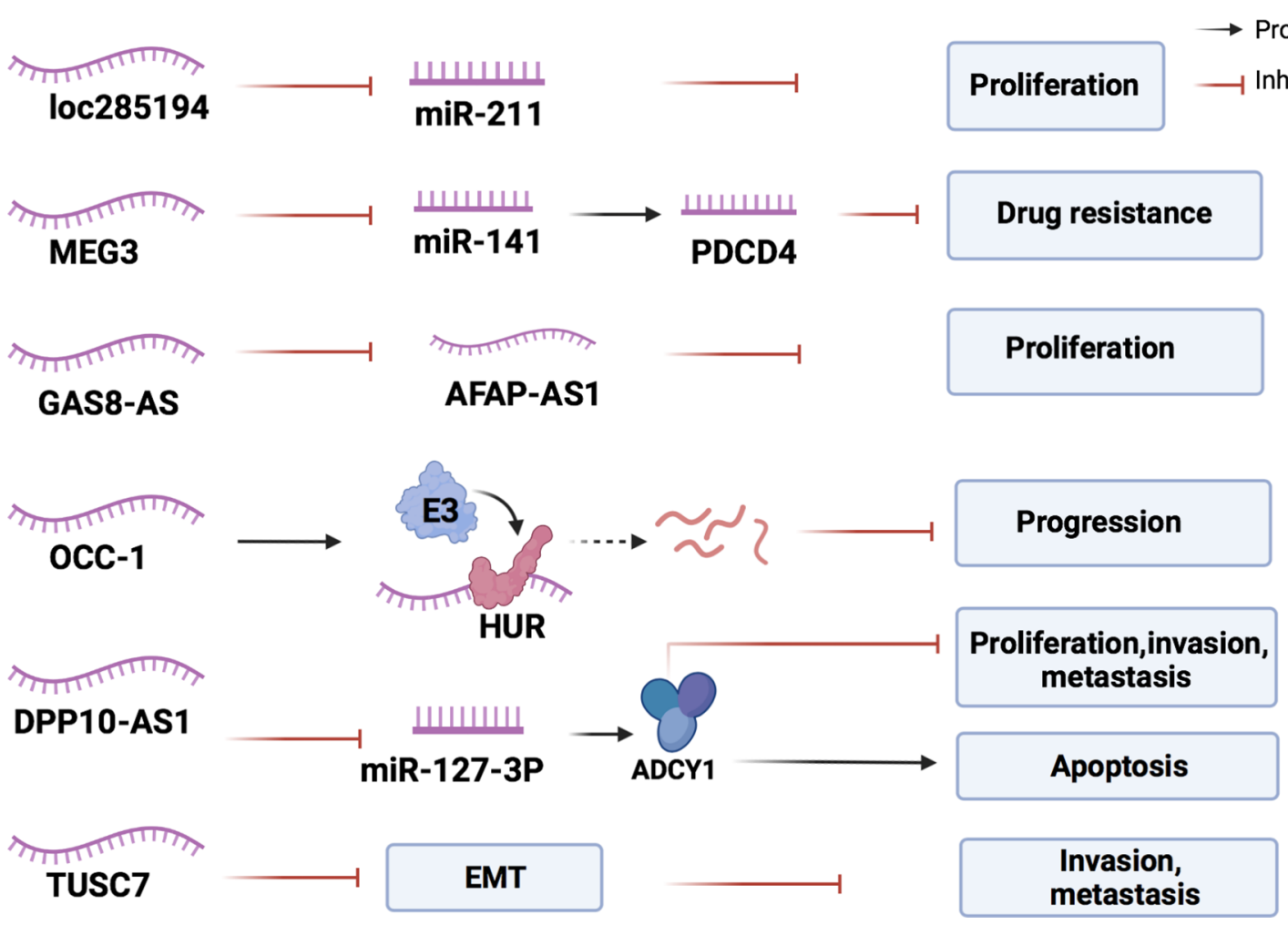

FIGURE 5 | The mechanisms of IncRNAs in inhibiting the development of CRC. Inhibitory IncRNAs influence the expression of miRNAs, IncRNAs, and proteins associated with CRC proliferation, and inhibit the intraepithelial mesenchymal transformation of CRC cells to resist cancer progression.

metastasis, and drug resistance, with a focus on the related signaling pathways, can help us to further understand CRC and develop better treatment strategies. For example, lncRNA HOX antisense intergenic RNA (HOTAIR) is involved in cancer cell proliferation, apoptosis, invasion, and metastasis, and its increased expression in the blood is associated with a high mortality rate (103-105). Propofol can inhibit lncRNA HOTAIR and is a potential drug for CRC treatment (106). lncRNA urothelial carcinoma associated 1 (UCA1) also plays a critical role in tumorigenesis (107), and it can be inhibited by metformin resulting in the apoptosis of CRC cells (108). Curcumin, which exists in the rhizomes of Curcuma longa, has been approved for the treatment of CRC $(109,110)$, and it can inhibit tumor occurrence by inducing the expression of a suppressor lncRNA neighbor of BRCA1 gene 2 (NBR2).
Recent studies have reported that lncRNAs can be encapsulated in exosomes and transmitted among tumor cells, regulating the occurrence and development of tumors. Exosomal lncRNAs show high organ specificity in the blood, urine, saliva, and tumor tissue and have the advantages of being non-invasive, repeatably detectable, and real-time monitoring. Thus, exosomal lncRNAs are expected to function as meaningful biomarkers (111-113). CRNDE-h is an exosomal lncRNA that can effectively distinguish CRC patients from benign colorectal diseases and NC subjects with significantly high sensitivity and specificity. In addition, the combination of several tumor markers, such as lncRNA ZFAS1, SNHG11, LINC00909, and LINC00654, can improve the accuracy of CRC diagnosis. Moreover, increased lncRNA SNHG11 helps to further screen and diagnose CRC (109). The SLS model

TABLE 3 | Inhibitory IncRNAs in CRC.

\begin{tabular}{|c|c|c|c|c|}
\hline IncRNAs & Expression & Function & Downstream targets & Reference \\
\hline Pint & $\downarrow$ & Inhibits proliferation & / & (63) \\
\hline Loc285194 & $\downarrow$ & Inhibits proliferation & mir-211 & (64) \\
\hline MEG3 & $\downarrow$ & Inhibits proliferation, metastasis, drug resistance & mir-141/PDCD4 & $(65,66)$ \\
\hline OCC-1 & $\downarrow$ & suppresses growth & HUR & (69) \\
\hline TUSC7 & $\downarrow$ & Inhibits metastasis & EMT & (73) \\
\hline DPP10-AS1 & $\downarrow$ & Inhibits metastasis, proliferation & mir-127-3p & $(74)$ \\
\hline
\end{tabular}


based on 52 lncRNAs can also predict the risk of CRC occurrence and mortality (110).

However, most studies at present can only indicate that there is a correlation between lncRNAs and CRC, but less clearly describes the specific mechanism between them. For the lncRNAs that have been studied, it is still difficult to determine which pathway is dominant, leading to increased challenges in choosing between targeted blocking or activation. A comprehensive understanding of the effects of lncRNAs on CRC has not been established, and studies on inhibitory lncRNAs are limited. It is necessary to consider the mechanism leading to the abnormal expression of lncRNAs in CRC. The upstream regulatory mechanisms of lncRNAs have not yet been fully elucidated. Therefore, new directions for future research may focus on the upstream regulatory factors of lncRNAs in CRC. These efforts may address the gaps in knowledge on lncRNA-related mechanisms and build a framework for understanding the effects of lncRNAs on CRC.

\section{REFERENCES}

1. Siegel RL, Miller KD, Goding Sauer A, Fedewa SA, Butterly LF, Anderson JC, et al. Colorectal Cancer Statistics, 2020. CA Cancer J Clin (2020) 70 (3):145-64. doi: 10.3322/caac.21601

2. Sung H, Ferlay J, Siegel RL, Laversanne M, Soerjomataram I, Jemal A, et al. Global Cancer Statistics 2020: GLOBOCAN Estimates of Incidence and Mortality Worldwide for 36 Cancers in 185 Countries. CA Cancer J Clin (2021) 71(3):209-49. doi: 10.3322/caac.21660

3. Ponting CP, Oliver PL. And Reik W. Evolution and Functions of Long Noncoding RNAs. Cell (2009) 136(4):629-41. doi: 10.1016/j.cell.2009.02.006

4. Ulitsky I, Bartel DP. lincRNAs: Genomics, Evolution, and Mechanisms. Cell (2013) 154(1):26-46. doi: 10.1016/j.cell.2013.06.020

5. Taniue K, Kurimoto A, Sugimasa H, Nasu E, Takeda Y, Iwasaki K, et al. Long Noncoding RNA UPAT Promotes Colon Tumorigenesis by Inhibiting Degradation of UHRF1. Proc Natl Acad Sci USA (2016) 113(5):1273-8. doi: 10.1073/pnas.1500992113

6. Bronner C, Krifa M, Mousli M. Increasing Role of UHRF1 in the Reading and Inheritance of the Epigenetic Code as Well as in Tumorogenesis. Biochem Pharmacol (2013) 86(12):1643-9. doi: 10.1016/j.bcp.2013.10.002

7. Masoumi-Moghaddam S, Amini A, Morris DL. The Developing Story of Sprouty and Cancer. Cancer Metastasis Rev (2014) 33(2-3):695-720. doi: 10.1007/s10555-014-9497-1

8. Pelletier J, Bellot G, Gounon P, Lacas-Gervais S, Pouysségur J. And Mazure N. M. Glycogen Synthesis is Induced in Hypoxia by the Hypoxia-Inducible Factor and Promotes Cancer Cell Survival. Front Oncol (2012) 2:18. doi: $10.3389 /$ fonc. 2012.00018

9. Sokolenko AP, Bulanova DR, Iyevleva AG, Aleksakhina SN, Preobrazhenskaya EV, Ivantsov AO, et al. High Prevalence of GPRC5A Germline Mutations in BRCA1-Mutant Breast Cancer Patients. Int J Cancer (2014) 134(10):2352-8. doi: 10.1002/ijc.28569

10. Margueron R, Reinberg D. The Polycomb Complex PRC2 and its Mark in Life. Nature (2011) 469(7330):343-9. doi: 10.1038/nature09784

11. Chase A, Cross NC. Aberrations of EZH2 in Cancer. Clin Cancer Res an OffJ Am Assoc Cancer Res (2011) 17(9):2613-8. doi: 10.1158/1078-0432.Ccr-102156

12. Comet I, Riising EM, Leblanc B, Helin K. Maintaining Cell Identity: PRC2Mediated Regulation of Transcription and Cancer. Nat Rev Cancer (2016) 16 (12):803-10. doi: 10.1038/nrc.2016.83

13. Li Y, Liu X, Cui X, Tan Y, Wang Q, Wang Y, et al. LncRNA PRADXMediated Recruitment of PRC2/DDX5 Complex Suppresses UBXN1 Expression and Activates NF- $\mathrm{kb}$ Activity, Promoting Tumorigenesis. Theranostics (2021) 11(9):4516-30. doi: 10.7150/thno.54549

\section{AUTHOR CONTRIBUTIONS}

SC, BH, and SZ were involved in the conception of the study. SC, YF, LS, and RH were involved in writing the article. SC, $\mathrm{BH}$, and SZ critically revised the manuscript. All authors read and approved the final manuscript. SC, YF, and LS contributed equally to this work.

\section{FUNDING}

This work was supported in part by the National Natural Science Foundation of China (81973598, 82074186, 82074214). Funding was also provided by the Medicine and Health Science and Technology Plan Projects in Zhejiang province (2021KY834), and Research Fund Project of Zhejiang Chinese Medical University (2019ZY02, 2020ZG41).

14. Wang YB, Tan B, Mu R, Chang Y, Wu M, Tu HQ, et al. UbiquitinAssociated Domain-Containing Ubiquitin Regulatory X (UBX) Protein UBXN1 is a Negative Regulator of Nuclear Factor $\kappa b$ (NF- $\kappa b)$ Signaling. J Biol Chem (2015) 290(16):10395-405. doi: 10.1074/jbc.M114.631689

15. Soleimani A, Rahmani F, Ferns GA, Ryzhikov M, Avan A. And Hassanian S M. Role of the NF- $\mathrm{b}$ S Signaling Pathway in the Pathogenesis of Colorectal Cancer. Gene (2020) 726:144132. doi: 10.1016/j.gene.2019.144132

16. Taniue K, Kurimoto A, Takeda Y, Nagashima T, Okada-Hatakeyama M, Katou Y, et al. ASBEL-TCF3 Complex Is Required for the Tumorigenicity of Colorectal Cancer Cells. Proc Natl Acad Sci USA (2016) 113(45):12739-44. doi: $10.1073 /$ pnas. 1605938113

17. Clevers H, Nusse R. Wnt/ $\beta$-Catenin Signaling and Disease. Cell (2012) 149 (6):1192-205. doi: 10.1016/j.cell.2012.05.012

18. Lien WH, Fuchs E. Wnt Some Lose Some: Transcriptional Governance of Stem Cells by Wnt/ $\beta$-Catenin Signaling. Genes Dev (2014) 28(14):1517-32. doi: $10.1101 /$ gad.244772.114

19. Holland JD, Klaus A, Garratt AN, Birchmeier W. Wnt Signaling in Stem and Cancer Stem Cells. Curr Opin Cell Biol (2013) 25(2):254-64. doi: 10.1016/ j.ceb.2013.01.004

20. Morin PJ. Beta-Catenin Signaling and Cancer. BioEssays News Rev mol Cell Dev Biol (1999) 21(12):1021-30. doi: 10.1002/(SICI)1521-1878(199912) 22:1<1021::AID-BIES6>3.0.CO;2-P

21. Meng Z, Moroishi T, Guan KL. Mechanisms of Hippo Pathway Regulation. Genes Dev (2016) 30(1):1-17. doi: 10.1101/gad.274027.115

22. Ou C, Sun Z, Li X, Li X, Ren W, Qin Z, et al. MiR-590-5p, a Density-Sensitive microRNA, Inhibits Tumorigenesis by Targeting YAP1 in Colorectal Cancer. Cancer Lett (2017) 399:53-63. doi: 10.1016/j.canlet.2017.04.011

23. Yu FX, Zhao B, Guan KL. Hippo Pathway in Organ Size Control, Tissue Homeostasis, and Cancer. Cell (2015) 163(4):811-28. doi: 10.1016/ j.cell.2015.10.044

24. Thomson DW, Dinger ME. Endogenous microRNA Sponges: Evidence and Controversy. Nat Rev Genet (2016) 17(5):272-83. doi: 10.1038/nrg.2016.20

25. Tay Y, Rinn J, Pandolfi PP. The Multilayered Complexity of ceRNA Crosstalk and Competition. Nature (2014) 505(7483):344-52. doi: 10.1038/nature12986

26. Hutvágner G, Zamore PD. A microRNA in a Multiple-Turnover RNAi Enzyme Complex. Sci (New York N.Y.) (2002) 297(5589):2056-60. doi: 10.1126/science.1073827

27. Zheng Y, Nie P, Xu S. Long Noncoding RNA CASC21 Exerts an Oncogenic Role in Colorectal Cancer Through Regulating miR-7-5p/YAP1 Axis. Biomed Pharmacother = Biomed Pharmacother (2020) 121:109628. doi: 10.1016/j.biopha.2019.109628

28. Matsumura K, Kawasaki Y, Miyamoto M, Kamoshida Y, Nakamura J, Negishi L, et al. The Novel G-Quadruplex-Containing Long Non-Coding 
RNA GSEC Antagonizes DHX36 and Modulates Colon Cancer Cell Migration. Oncogene (2017) 36(9):1191-9. doi: 10.1038/onc.2016.282

29. Xu M, Chen X, Lin K, Zeng K, Liu X, Pan B, et al. The Long Noncoding RNA SNHG1 Regulates Colorectal Cancer Cell Growth Through Interactions With EZH2 and miR-154-5p. Mol Cancer (2018) 17(1):141. doi: 10.1186/ s12943-018-0894-x

30. Tang J, Yan T, Bao Y, Shen C, Yu C, Zhu X, et al. LncRNA GLCC1 Promotes Colorectal Carcinogenesis and Glucose Metabolism by Stabilizing C-Myc. Nat Commun (2019) 10(1):3499. doi: 10.1038/s41467-019-11447-8

31. Hanahan D, Weinberg RA. Hallmarks of Cancer: The Next Generation. Cell (2011) 144(5):646-74. doi: 10.1016/j.cell.2011.02.013

32. Whitesell L, Lindquist SL. HSP90 and the Chaperoning of Cancer. Nat Rev Cancer (2005) 5(10):761-72. doi: 10.1038/nrc1716

33. Grandclement C, Pallandre JR, Valmary Degano S, Viel E, Bouard A, Balland J, et al. Neuropilin-2 Expression Promotes TGF- $\beta 1$-Mediated Epithelial to Mesenchymal Transition in Colorectal Cancer Cells. PloS One (2011) 6(7):e20444. doi: 10.1371/journal.pone.0020444

34. Graham LD, Pedersen SK, Brown GS, Ho T, Kassir Z, Moynihan AT, et al. Colorectal Neoplasia Differentially Expressed (CRNDE), a Novel Gene With Elevated Expression in Colorectal Adenomas and Adenocarcinomas. Genes Cancer (2011) 2(8):829-40. doi: 10.1177/1947601911431081

35. Han P, Li JW, Zhang BM, Lv JC, Li YM, Gu XY, et al. The IncRNA CRNDE Promotes Colorectal Cancer Cell Proliferation and Chemoresistance via miR-181a-5p-Mediated Regulation of Wnt/ $\beta$-Catenin Signaling. Mol Cancer (2017) 16(1):9. doi: 10.1186/s12943-017-0583-1

36. Sase T, Suzuki T, Miura K, Shiiba K, Sato I, Nakamura Y, et al. Runt-Related Transcription Factor 2 in Human Colon Carcinoma: A Potent Prognostic Factor Associated With Estrogen Receptor. Int J Cancer (2012) 131 (10):2284-93. doi: 10.1002/ijc.27525

37. Slattery ML, Lundgreen A, Herrick JS, Caan BJ, Potter JD, Wolff RK. Associations Between Genetic Variation in RUNX1, RUNX2, RUNX3, MAPK1 and Eif4e and Riskof Colon and Rectal Cancer: Additional Support for a TGF- $\beta$-Signaling Pathway. Carcinogenesis (2011) 32(3):31826. doi: $10.1093 /$ carcin/bgq245

38. Zhu JH, Hong DF, Song YM, Sun LF, Wang ZF, Wang JW. Suppression of Cellular Apoptosis Susceptibility (CSE1L) Inhibits Proliferation and Induces Apoptosis in Colorectal Cancer Cells. Asian Pac J Cancer Prev APJCP (2013) 14(2):1017-21. doi: 10.7314/apjcp.2013.14.2.1017

39. Yu Y, Nangia-Makker P, Farhana L, Majumdar APN. A Novel Mechanism of lncRNA and miRNA Interaction: CCAT2 Regulates miR-145 Expression by Suppressing its Maturation Process in Colon Cancer Cells. Mol Cancer (2017) 16(1):155. doi: 10.1186/s12943-017-0725-5

40. Wang W, Martindale JL, Yang X, Chrest FJ, Gorospe M. Increased Stability of the P16 mRNA With Replicative Senescence. EMBO Rep (2005) 6(2):15864. doi: $10.1038 /$ sj.embor. 7400346

41. Doherty JR, Cleveland JL. Targeting Lactate Metabolism for Cancer Therapeutics. J Clin Invest (2013) 123(9):3685-92. doi: 10.1172/jci69741

42. Shim H, Dolde C, Lewis BC, Wu CS, Dang G, Jungmann RA, et al. C-Myc Transactivation of LDH-A: Implications for Tumor Metabolism and Growth. Proc Natl Acad Sci USA (1997) 94(13):6658-63. doi: 10.1073/ pnas. 94.13 .6658

43. Liu A, Liu L, Lu H. LncRNA XIST Facilitates Proliferation and EpithelialMesenchymal Transition of Colorectal Cancer Cells Through Targeting miR-486-5p and Promoting Neuropilin-2. J Cell Physiol (2019) 234 (8):13747-61. doi: 10.1002/jcp.28054

44. Liu C, Li M, Hu Y, Shi N, Yu H, Liu H, et al. miR-486-5p Attenuates Tumor Growth and Lymphangiogenesis by Targeting Neuropilin-2 in Colorectal Carcinoma. OncoTargets Ther (2016) 9:2865-71. doi: 10.2147/ott.S103460

45. Dacheng W, Songhe L, Weidong J, Shutao Z, Jinging L, Jiaming Z. LncRNA SNHG3 Promotes the Growth and Metastasis of Colorectal Cancer by Regulating miR-539/RUNX2 Axis. Biomed Pharmacother $=$ Biomed Pharmacother (2020) 125:110039. doi: 10.1016/j.biopha.2020.110039

46. Ma S, Yang D, Liu Y, Wang Y, Lin T, Li Y, et al. LncRNA BANCR Promotes Tumorigenesis and Enhances Adriamycin Resistance in Colorectal Cancer. Aging (Albany NY) (2018) 10(8):2062-78. doi: 10.18632/aging.101530

47. Alnabulsi A, Agouni A, Mitra S, Garcia-Murillas I, Carpenter B, Bird S, et al. Cellular Apoptosis Susceptibility (Chromosome Segregation 1-Like, CSE1L)
Gene is a Key Regulator of Apoptosis, Migration and Invasion in Colorectal Cancer. J Pathol (2012) 228(4):471-81. doi: 10.1002/path.4031

48. Ma W, Qiao J, Zhou J, Gu L, Deng D. Characterization of Novel LncRNA P14AS as a Protector of ANRIL Through AUF1 Binding in Human Cells. Mol Cancer (2020) 19(1):42. doi: 10.1186/s12943-020-01150-4

49. Huang J, Zhang A, Ho TT, Zhang Z, Zhou N, Ding X, et al. Linc-RoR Promotes C-Myc Expression Through hnRNP I and AUF1. Nucleic Acids Res (2016) 44(7):3059-69. doi: 10.1093/nar/gkv1353

50. Yoon JH, De S, Srikantan S, Abdelmohsen K, Grammatikakis I, Kim J, et al. PAR-CLIP Analysis Uncovers AUF1 Impact on Target RNA Fate and Genome Integrity. Nat Commun (2014) 5:5248. doi: 10.1038/ncomms6248

51. Naemura M, Tsunoda T, Inoue Y, Okamoto H, Shirasawa S, Kotake Y. ANRIL Regulates the Proliferation of Human Colorectal Cancer Cells in Both Two- and Three-Dimensional Culture. Mol Cell Biochem (2016) 412(12):141-6. doi: 10.1007/s11010-015-2618-5

52. Meseure D, Vacher S, Alsibai KD, Nicolas A, Chemlali W, Caly M, et al. Expression of ANRIL-Polycomb Complexes-CDKN2A/B/ARF Genes in Breast Tumors: Identification of a Two-Gene (EZH2/CBX7) Signature With Independent Prognostic Value. Mol Cancer Res MCR (2016) 14 (7):623-33. doi: 10.1158/1541-7786.Mcr-15-0418

53. Tsai KW, Lo YH, Liu H, Yeh CY, Chen YZ, Hsu CW, et al. Linc00659, a Long Noncoding RNA, Acts as Novel Oncogene in Regulating Cancer Cell Growth in Colorectal Cancer. Mol Cancer (2018) 17(1):72. doi: 10.1186/ s12943-018-0821-1

54. Wang JH, Lu TJ, Kung ML, Yang YF, Yeh CY, Tu YT, et al. The Long Noncoding RNA LOC441461 (STX17-AS1) Modulates Colorectal Cancer Cell Growth and Motility. Cancers (2020) 12(11):3171. doi: 10.3390/ cancers 12113171

55. Yang L, Qiu M, Xu Y, Wang J, Zheng Y, Li M, et al. Upregulation of Long non-Coding RNA PRNCR1 in Colorectal Cancer Promotes Cell Proliferation and Cell Cycle Progression. Oncol Rep (2016) 35(1):318-24. doi: 10.3892/or.2015.4364

56. Black AR, Black JD, Azizkhan-Clifford J. Sp1 and Krüppel-Like Factor Family of Transcription Factors in Cell Growth Regulation and Cancer. J Cell Physiol (2001) 188(2):143-60. doi: 10.1002/jcp.1111

57. Yue B, Liu C, Sun H, Liu M, Song C, Cui R, et al. A Positive Feed-Forward Loop Between LncRNA-CYTOR and Wnt/B-Catenin Signaling Promotes Metastasis of Colon Cancer. Mol Ther J Am Soc Gene Ther (2018) 26 (5):1287-98. doi: 10.1016/j.ymthe.2018.02.024

58. Silva-Fisher JM, Dang HX, White NM, Strand MS, Krasnick BA, Rozycki EB, et al. Long Non-Coding RNA RAMS11 Promotes Metastatic Colorectal Cancer Progression. Nat Commun (2020) 11(1):2156. doi: 10.1038/s41467020-15547-8

59. El-Deiry WS, Vijayvergia N, Xiu J, Scicchitano A, Lim B, Yee NS, et al. Molecular Profiling of 6,892 Colorectal Cancer Samples Suggests Different Possible Treatment Options Specific to Metastatic Sites. Cancer Biol Ther (2015) 16(12):1726-37. doi: 10.1080/15384047.2015.1113356

60. Miura JT, Xiu J, Thomas J, George B, Carron BR, Tsai S, et al. Tumor Profiling of Gastric and Esophageal Carcinoma Reveal Different Treatment Options. Cancer Biol Ther (2015) 16(5):764-9. doi: 10.1080/ 15384047.2015.1026479

61. Li X, Liu Y, Chen W, Fang Y, Xu H, Zhu HH, et al. TOP2Ahigh is the Phenotype of Recurrence and Metastasis Whereas TOP2Aneg Cells Represent Cancer Stem Cells in Prostate Cancer. Oncotarget (2014) 5 (19):9498-513. doi: 10.18632/oncotarget.2411

62. Fountzilas G, Christodoulou C, Bobos M, Kotoula V, Eleftheraki AG Xanthakis I, et al. Topoisomerase II Alpha Gene Amplification is a Favorable Prognostic Factor in Patients With HER2-Positive Metastatic Breast Cancer Treated With Trastuzumab. J Trans Med (2012) 10:212. doi: 10.1186/1479-5876-10-212

63. Pei YF, Yin XM, Liu XQ. TOP2A Induces Malignant Character of Pancreatic Cancer Through Activating $\beta$-Catenin Signaling Pathway. Biochim Biophys Acta Mol Basis Dis (2018) 1864(1):197-207. doi: 10.1016/j.bbadis.2017.10.019

64. Norimura S, Kontani K, Kubo T, Hashimoto SI, Murazawa C, Kenzaki K, et al. Candidate Biomarkers Predictive of Anthracycline and Taxane Efficacy Against Breast Cancer. J Cancer Res Ther (2018) 14(2):409-15. doi: 10.4103/ jcrt.JCRT_1053_16 
65. Nygård SB, Christensen IJ, Smith DH, Nielsen SL, Jensen NF, Nielsen HJ, et al. Underpinning the Repurposing of Anthracyclines Towards Colorectal Cancer: Assessment of Topoisomerase II Alpha Gene Copy Number Alterations in Colorectal Cancer. Scand J Gastroenterol (2013) 48 (12):1436-43. doi: 10.3109/00365521.2013.848230

66. Sønderstrup IM, Nygård SB, Poulsen TS, Linnemann D, Stenvang J, Nielsen $\mathrm{HJ}$, et al. Topoisomerase- 1 and -2A Gene Copy Numbers are Elevated in Mismatch Repair-Proficient Colorectal Cancers. Mol Oncol (2015) 9 (6):1207-17. doi: 10.1016/j.molonc.2015.02.009

67. Tsavaris N, Lazaris A, Kosmas C, Gouveris P, Kavantzas N, Kopterides P, et al. Topoisomerase I and IIalpha Protein Expression in Primary Colorectal Cancer and Recurrences Following 5-Fluorouracil-Based Adjuvant Chemotherapy. Cancer Chemother Pharmacol (2009) 64(2):391-8. doi: 10.1007/s00280-008-0886-4

68. Mo S, Zhang L, Dai W, Han L, Wang R, Xiang W, et al. Antisense lncRNA LDLRAD4-AS1 Promotes Metastasis by Decreasing the Expression of LDLRAD4 and Predicts a Poor Prognosis in Colorectal Cancer. Cell Death Dis (2020) 11(2):155. doi: 10.1038/s41419-020-2338-y

69. Ishiwata T. Cancer Stem Cells and Epithelial-Mesenchymal Transition: Novel Therapeutic Targets for Cancer. Pathol Int (2016) 66(11):601-8. doi: 10.1111/pin.12447

70. Bates RC, Pursell BM, Mercurio AM. Epithelial-Mesenchymal Transition and Colorectal Cancer: Gaining Insights Into Tumor Progression Using LIM 1863 Cells. Cells Tissues Organs (2007) 185(1-3):29-39. doi: 10.1159/ 000101300

71. Bates RC. Colorectal Cancer Progression: Integrin Alphavbeta6 and the Epithelial-Mesenchymal Transition (EMT). Cell Cycle (Georgetown Tex.) (2005) 4(10):1350-2. doi: 10.4161/cc.4.10.2053

72. Kawasaki Y, Miyamoto M, Oda T, Matsumura K, Negishi L, Nakato R, et al. The Novel IncRNA CALIC Upregulates AXL to Promote Colon Cancer Metastasis. EMBO Rep (2019) 20(8):e47052. doi: 10.15252/embr.201847052

73. Goruppi S, Ruaro E, Varnum B, Schneider C. Gas6-Mediated Survival in NIH3T3 Cells Activates Stress Signalling Cascade and is Independent of Ras. Oncogene (1999) 18(29):4224-36. doi: 10.1038/sj.onc.1202788

74. Grommes C, Lee CY, Wilkinson BL, Jiang Q, Koenigsknecht-Talboo JL, Varnum B, et al. Regulation of Microglial Phagocytosis and Inflammatory Gene Expression by Gas6 Acting on the Axl/Mer Family of Tyrosine Kinases. I Neuroimmune Pharmacol Off J Soc NeuroImmune Pharmacol (2008) 3(2):130-40. doi: 10.1007/s11481-007-9090-2

75. Ni X, Ding Y, Yuan H, Shao J, Yan Y, Guo R, et al. Long non-Coding RNA ZEB1-AS1 Promotes Colon Adenocarcinoma Malignant Progression via miR-455-3p/PAK2 Axis. Cell Proliferation (2020) 53(1):e12723. doi: $10.1111 /$ cpr.12723

76. Gadepalli R, Kotla S, Heckle MR, Verma SK, Singh NK, Rao GN. Novel Role for P21-Activated Kinase 2 in Thrombin-Induced Monocyte Migration. J Biol Chem (2013) 288(43):30815-31. doi: 10.1074/jbc.M113.463414

77. Liu J, Zhan Y, Wang J, Wang J, Guo J, Kong D. Long Noncoding RNA LINC01578 Drives Colon Cancer Metastasis Through a Positive Feedback Loop With the NF-Kb/YY1 Axis. Mol Oncol (2020) 14(12):3211-33. doi: $10.1002 / 1878-0261.12819$

78. Shiraiwa K, Matsuse M, Nakazawa Y, Ogi T, Suzuki K, Saenko V, et al. JAK/ STAT3 and NF-kb Signaling Pathways Regulate Cancer Stem-Cell Properties in Anaplastic Thyroid Cancer Cells. Thyroid Off J Am Thyroid Assoc (2019) 29(5):674-82. doi: 10.1089/thy.2018.0212

79. Cherry EM, Lee DW, Jung JU, Sitcheran R. Tumor Necrosis Factor-Like Weak Inducer of Apoptosis (TWEAK) Promotes Glioma Cell Invasion Through Induction of NF-kb-Inducing Kinase (NIK) and Noncanonical NF-kb Signaling. Mol Cancer (2015) 14(1):9. doi: 10.1186/s12943-014-0273-1

80. Punt CJ, Tol J. More is Less - Combining Targeted Therapies in Metastatic Colorectal Cancer. Nat Rev Clin Oncol (2009) 6(12):731-3. doi: 10.1038/ nrclinonc.2009.168

81. Ren J, Ding L, Zhang D, Shi G, Xu Q, Shen S, et al. Carcinoma-Associated Fibroblasts Promote the Stemness and Chemoresistance of Colorectal Cancer by Transferring Exosomal lncRNA H19. Theranostics (2018) 8 (14):3932-48. doi: 10.7150/thno.25541

82. Minn I, Wang H, Mease RC, Byun Y, Yang X, Wang J, et al. A Red-Shifted Fluorescent Substrate for Aldehyde Dehydrogenase. Nat Commun (2014) 5:3662. doi: $10.1038 /$ ncomms4662
83. Li P, Zhang X, Wang H, Wang L, Liu T, Du L, et al. MALAT1 Is Associated With Poor Response to Oxaliplatin-Based Chemotherapy in Colorectal Cancer Patients and Promotes Chemoresistance Through EZH2. Mol Cancer Ther (2017) 16(4):739-51. doi: 10.1158/1535-7163.Mct-16-0591

84. Cao Q, Yu J, Dhanasekaran SM, Kim JH, Mani RS, Tomlins SA, et al. Repression of E-Cadherin by the Polycomb Group Protein EZH2 in Cancer. Oncogene (2008) 27(58):7274-84. doi: 10.1038/onc.2008.333

85. Gordon DJ, Resio B, Pellman D. Causes and Consequences of Aneuploidy in Cancer. Nat Rev Genet (2012) 13(3):189-203. doi: 10.1038/nrg3123

86. Chen B, Dragomir MP, Fabris L, Bayraktar R, Knutsen E, Liu X, et al. The Long Noncoding RNA CCAT2 Induces Chromosomal Instability Through BOP1-AURKB Signaling. Gastroenterology (2020) 159(6):2146-2162.e2133. doi: 10.1053/j.gastro.2020.08.018

87. Yue B, Cai D, Liu C, Fang C, Yan D. Linc00152 Functions as a Competing Endogenous RNA to Confer Oxaliplatin Resistance and Holds Prognostic Values in Colon Cancer. Mol Ther J Am Soc Gene Ther (2016) 24(12):206477. doi: $10.1038 / \mathrm{mt} .2016 .180$

88. Luo P, Wu S, Ji K, Yuan X, Li H, Chen J, et al. LncRNA MIR4435-2HG Mediates Cisplatin Resistance in HCT116 Cells by Regulating Nrf2 and HO1. PloS One (2020) 15(11):e0223035. doi: 10.1371/journal.pone.0223035

89. Nguyen T, Nioi P, Pickett CB. The Nrf2-Antioxidant Response Element Signaling Pathway and its Activation by Oxidative Stress. J Biol Chem (2009) 284(20):13291-5. doi: 10.1074/jbc.R900010200

90. Na HK, Surh YJ. Oncogenic Potential of Nrf2 and its Principal Target Protein Heme Oxygenase-1. Free Radical Biol Med (2014) 67:353-65. doi: 10.1016/j.freeradbiomed.2013.10.819

91. Furfaro AL, Traverso N, Domenicotti C, Piras S, Moretta L, Marinari UM, et al. The Nrf2/HO-1 Axis in Cancer Cell Growth and Chemoresistance. Oxid Med Cell Longevity (2016) 2016:1958174. doi: 10.1155/2016/1958174

92. Xu G, Zhu H, Xu J, Wang Y, Zhang Y, Zhang M, et al. Long non-Coding RNA POU6F2-AS2 Promotes Cell Proliferation and Drug Resistance in Colon Cancer by Regulating miR-377/Brd4. J Cell Mol Med (2020) 24 (7):4136-49. doi: 10.1111/jcmm.15070

93. Marín-Béjar O, Marchese FP, Athie A, Sánchez Y, González J, Segura V, et al. Pint lincRNA Connects the P53 Pathway With Epigenetic Silencing by the Polycomb Repressive Complex 2. Genome Biol (2013) 14(9):R104. doi: 10.1186/gb-2013-14-9-r104

94. Liu Q, Huang J, Zhou N, Zhang Z, Zhang A, Lu Z, et al. LncRNA Loc285194 is a P53-Regulated Tumor Suppressor. Nucleic Acids Res (2013) 41(9):497687. doi: $10.1093 /$ nar/gkt182

95. Wu X, Li J, Ren Y, Zuo Z, Ni S, Cai J. MEG3 can Affect the Proliferation and Migration of Colorectal Cancer Cells Through Regulating miR-376/PRKD1 Axis. Am J Trans Res (2019) 11(9):5740-51.

96. Wang H, Li H, Zhang L, Yang D. Overexpression of MEG3 Sensitizes Colorectal Cancer Cells to Oxaliplatin Through Regulation of miR-141/ PDCD4 Axis. Biomed Pharmacother = Biomed Pharmacother (2018) 106:1607-15. doi: 10.1016/j.biopha.2018.07.131

97. Lan Y, Xiao X, He Z, Luo Y, Wu C, Li L, et al. Long Noncoding RNA OCC-1 Suppresses Cell Growth Through Destabilizing HuR Protein in Colorectal Cancer. Nucleic Acids Res (2018) 46(11):5809-21. doi: 10.1093/nar/gky214

98. Lebedeva S, Jens $M$, Theil K, Schwanhäusser B, Selbach M, Landthaler M, et al. Transcriptome-Wide Analysis of Regulatory Interactions of the RNABinding Protein HuR. Mol Cell (2011) 43(3):340-52. doi: 10.1016/ j.molcel.2011.06.008

99. Li T, Huang H, Shi G, Zhao L, Li T, Zhang Z, et al. TGF- $\beta 1-S O X 9$ AxisInducible COL10A1 Promotes Invasion and Metastasis in Gastric Cancer via Epithelial-to-Mesenchymal Transition. Cell Death Dis (2018) 9(9):849. doi: 10.1038/s41419-018-0877-2

100. Song N, Zhong J, Hu Q, Gu T, Yang B, Zhang J, et al. FGF18 Enhances Migration and the Epithelial-Mesenchymal Transition in Breast Cancer by Regulating Akt/Gsk3ß/B-Catenin Signaling. Cell Physiol Biochem Int J Exp Cell Physiol Biochem Pharmacol (2018) 49(3):1019-32. doi: 10.1159/ 000493286

101. Zhang H, Song Y, Yang C, Wu X. Overexpression of lncRNA TUSC7 Reduces Cell Migration and Invasion in Colorectal Cancer. Oncol Rep (2019) 41(6):3386-92. doi: 10.3892/or.2019.7106

102. Liu G, Zhao H, Song Q, Li G, Lin S, Xiong S. Long non-Coding RNA DPP10AS1 Exerts Anti-Tumor Effects on Colon Cancer via the Upregulation of 
ADCY1 by Regulating microRNA-127-3p. Aging (Albany NY) (2021) 13 (7):9748-65. doi: 10.18632/aging.202729

103. Tang Q, Hann SS. HOTAIR: An Oncogenic Long Non-Coding RNA in Human Cancer. Cell Physiol Biochem Int J Exp Cell Physiol Biochem Pharmacol (2018) 47(3):893-913. doi: 10.1159/000490131

104. Kogo R, Shimamura T, Mimori K, Kawahara K, Imoto S, Sudo T, et al. Long Noncoding RNA HOTAIR Regulates Polycomb-Dependent Chromatin Modification and is Associated With Poor Prognosis in Colorectal Cancers. Cancer Res (2011) 71(20):6320-6. doi: 10.1158/0008-5472.Can11-1021

105. Svoboda M, Slyskova J, Schneiderova M, Makovicky P, Bielik L, Levy M, et al. HOTAIR Long non-Coding RNA is a Negative Prognostic Factor Not Only in Primary Tumors, But Also in the Blood of Colorectal Cancer Patients. Carcinogenesis (2014) 35(7):1510-5. doi: 10.1093/carcin/bgu055

106. Zhang YF, Li CS, Zhou Y, Lu XH. Effects of Propofol on Colon Cancer Metastasis Through STAT3/HOTAIR Axis by Activating WIF-1 and Suppressing Wnt Pathway. Cancer Med (2020) 9(5):1842-54. doi: 10.1002/ cam4.2840

107. Cui M, Chen M, Shen Z, Wang R, Fang X, Song B. LncRNA-UCA1 Modulates Progression of Colon Cancer Through Regulating the miR-285p/HOXB3 Axis. J Cell Biochem (2019) 120:6926-36. doi: 10.1002/jcb.27630

108. Guo J, Li Y, Duan H, Yuan L. Metformin Suppresses the Proliferation and Promotes the Apoptosis of Colon Cancer Cells Through Inhibiting the Expression of Long Noncoding RNA-Uca1. OncoTargets Ther (2020) 13:4169-81. doi: 10.2147/ott.S245091

109. Xu W, Zhou G, Wang H, Liu Y, Chen B, Chen W, et al. Circulating lncRNA SNHG11 as a Novel Biomarker for Early Diagnosis and Prognosis of Colorectal Cancer. Int J Cancer (2020) 146(10):2901-12. doi: 10.1002/ijc.32747

110. Zhou R, Sun H, Zheng S, Zhang J, Zeng D, Wu J, et al. A Stroma-Related lncRNA Panel for Predicting Recurrence and Adjuvant Chemotherapy
Benefit in Patients With Early-Stage Colon Cancer. J Cell Mol Med (2020) 24(5):3229-41. doi: 10.1111/jcmm.14999

111. Takahashi K, Yan IK, Wood J, Haga H, Patel T. Involvement of Extracellular Vesicle Long Noncoding RNA (Linc-VLDLR) in Tumor Cell Responses to Chemotherapy. Mol Cancer Res MCR (2014) 12(10):1377-87. doi: 10.1158/ 1541-7786.Mcr-13-0636

112. Takahashi K, Yan IK, Kogure T, Haga H, Patel T. Extracellular VesicleMediated Transfer of Long non-Coding RNA ROR Modulates Chemosensitivity in Human Hepatocellular Cancer. FEBS Open Bio (2014) 4:458-67. doi: 10.1016/j.fob.2014.04.007

113. Işın M, Uysaler E, Özgür E, Köseoğlu H, Şanlı Ö., Yücel ÖB, et al. Exosomal IncRNA-P21 Levels may Help to Distinguish Prostate Cancer From Benign Disease. Front Genet (2015) 6:168. doi: 10.3389/fgene.2015.00168

Conflict of Interest: The authors declare that the research was conducted in the absence of any commercial or financial relationships that could be construed as a potential conflict of interest.

Publisher's Note: All claims expressed in this article are solely those of the authors and do not necessarily represent those of their affiliated organizations, or those of the publisher, the editors and the reviewers. Any product that may be evaluated in this article, or claim that may be made by its manufacturer, is not guaranteed or endorsed by the publisher.

Copyright $\odot 2021$ Chen, Fang, Sun, He, He and Zhang. This is an open-access article distributed under the terms of the Creative Commons Attribution License (CC BY). The use, distribution or reproduction in other forums is permitted, provided the original author(s) and the copyright owner(s) are credited and that the original publication in this journal is cited, in accordance with accepted academic practice. No use, distribution or reproduction is permitted which does not comply with these terms. 